\title{
Potencial fotossensibilizante de extratos de plantas do agreste na técnica de terapia fotodinâmica
}

\author{
Photosensibilizing potential of plant extracts \\ of agreste in photodynamic therapy technique
}

\author{
Bárbara de Oliveira SiqueIRA ${ }^{1}$ \\ Andrezza Mayara Venâncio Cadengue ${ }^{2}$ \\ Talita Camila Evaristo da Silva Nascimento ${ }^{3}$ \\ Gualberto Segundo Agamez Montalvo ${ }^{4}$ \\ RosÂngela Estevão Alves Falcão ${ }^{5}$ \\ Keila Aparecida Moreira ${ }^{6}$ \\ Patrícia Lins AzeVedo do Nascimento ${ }^{7}$
}

\section{RESUMO}

Objetivo: Avaliar in vitro a ação dos extratos de Myracrodruon urundeuva, Stryphnodendron adstringens e Sideroxylon obtusifolium como fotossensibilizantes da Terapia Fotodinâmica (TFD). Métodos: A atividade antimicrobiana frente Staphylococcus aureus foi testada utilizando uma matriz de planejamento fatorial $2^{3} \mathrm{com}$ a finalidade de exibir os pontos experimentais nos distintos níveis das variáveis independentes, sendo estas: tempo de pré-irradiação, concentração do fotossensibilizante e tempo de irradiação. $\mathrm{E}$ os resultados foram avaliados através do modelo de regressão logístico no software R. Nos ensaios a fonte de luz empregada foi o laser vermelho InGaAIP no comprimento de onda de $660 \mathrm{~nm}$ e fluência de 70, 140 e 210 $\mathrm{J} / \mathrm{cm}^{2}$, na potência de $100 \mathrm{~mW}$. Após a aplicação do laser, o conteúdo dos poços foi semeado em placas de Petri contendo Agar Müeller Hinton, incubadas em estufa microbiológica a $37^{\circ} \mathrm{C}$ por 24 horas. Em seguida, a leitura das placas foi realizada usando o conceito de crescimento ou não de unidades formadoras de colônias. Resultados: Houve maior tendência de inibição bacteriana quando o tempo de pré-irradiação foi 5 minutos, concentração do extrato de $100 \mu \mathrm{g} / \mathrm{mL}$ e tempo de irradiação de 60 segundos, utilizando os extratos de $M$. urundeuva e S. adstringens. Entretanto, S. obtusifolium não apresentou eficiência fotossensibilizante. Conclusão: Dentro das condições avaliadas, dois dos extratos de plantas testados apresenta potencial como agente fotossensibilizante na terapia fotodinâmica. Sendo possível apresentar para os mesmos modelos estatísticos de predição adequada para a atividade antimicrobiana nas condições estudadas.

Palavras-chaves: Terapia fotodinâmica. Extratos vegetais. Agentes fotossensibilizantes. Modelos estatísticos.

Graduanda em Odontologia do Centro Universitário Tabosa de Almeida/ ASCES-UNITA.Participação pessoal: Elaboração do manuscrito e desenvolvimento experimental.

2 Graduanda em Odontologia do Centro Universitário Tabosa de Almeida/ ASCES-UNITA.Participação pessoal: Elaboração do manuscrito e desenvolvimento experimental.

3 Doutora em Biociência Animal pela Universidade Federal Rural de Pernambuco.Participação pessoal: Desenvolvimento experimental e edições do texto.

4 Professor Adjunto do Departamento de estatística e matemática aplicada da Universidade Federal do Ceará, Brasil.Participação pessoal: Análises estatísticas e edições do texto.

5 Professora adjunta do curso de Licenciatura em Ciências Biológicas da Universidade de Pernambuco, Campus Garanhuns. Participação pessoal: Coleta das plantas e obtenção dos extratos.

6 Professora Adjunta do Curso de Medicina Veterinária da Unidade Acadêmica de Garanhuns da Universidade Federal Rural de Pernambuco.Participação pessoal: Obtenção dos extratos.

7 Professora Assistente III do Curso de Odontologia do Centro Universitário Tabosa de Almeida/ ASCES-UNITA. 


\begin{abstract}
Objective: To evaluate in vitro the extracts of Myracrodruon urundeuva, Stryphnodendron adstringens and Sideroxylon obtusifolium as photosensitizers of photodynamic therapy (PDT). Methods: The antimicrobial activity against Staphylococcus aureus was tested using a factorial design matrix $2^{3}$ with the purpose of displaying the experimental points in the different levels of the independent variables, being: pre-irradiation time, photosensitizing concentration and irradiation time. In the tests the light source used was the red laser InGaAIP in the wavelength of $660 \mathrm{~nm}$ and fluency of 70,140 and $210 \mathrm{~J} / \mathrm{cm}^{2}$, in the power of $100 \mathrm{~mW}$. After laser application, the contents of the wells were seeded in Petri dishes containing Müller Hinton Agar, incubated in a microbiological oven at $37^{\circ} \mathrm{C}$ for 24 hours. Then the plates were read using the concept of growing or not of colony forming units. Results: There was a greater tendency of bacterial inhibition when the pre-irradiation time was 5 minutes, extract concentration of $100 \mu \mathrm{g} / \mathrm{mL}$ and irradiation time of 60 seconds, using the extracts of $M$. urundeuva and S. adstringens. However, S. obtusifolium did not show photosensitizing efficiency. Conclusion: Within the evaluated conditions, two of the plant extracts tested have potential as a photosensitizing agent in photodynamic therapy. It is possible to present to the same statistical models of prediction adequate for antimicrobial activity under the conditions studied.
\end{abstract}

Keywords: Photodynamic therapy. Plant extracts. Photosensitizing agents. Statistical models.

\section{INTRODUÇÃO}

\section{A Terapia Fotodinâmica (TFD) surgiu} como uma opção terapêutica não invasiva para o tratamento de doenças infecciosas. Esta terapia consiste na ativação de um corante fotossensibilizante com uma fonte de luz num comprimento de onda visível apropriado. ${ }^{1}$ As demandas da TFD apresentam três elementos básicos: fotossensibilizadores responsáveis para a sensibilidade do tecido doente, fonte de luz causando mobilização de fotossensibilizadores e oxigênio dissolvido em tecido sendo tratados. Podendo-se dizer que a TFD depende diretamente da interação entre esses componentes. ${ }^{2}$

$\mathrm{Na}$ odontologia, a grande maioria das patologias está relacionada a bactérias, fungos e vírus; de modo que, a TFD apresenta-se promissora com diversas aplicações e inúmeras vantagens, dentre elas o custo, a ausência de efeitos colaterais e a impossibilidade de resistência adquirida por bactérias. É utilizada como coadjuvante de antibióticos na eliminação de bactérias periopatogênicas. Em termos gerais, representa uma alternativa antibacteriana, antifúngica e antiviral para os micro-organismos resistentes a fármacos. ${ }^{3}$
Os fotossensibilizantes (FS) utilizados na TFD devem apresentar comportamento biológico estável, ter caráter minimamente tóxico para tecidos do organismo, ser fotoquimicamente ativo, exibir seletividade pela célula-alvo, ser administrado de forma local, tópica, ou no interior da cavidade e, depois de um tempo ideal, ser irradiado com luz em dose e comprimento de onda adequados. ${ }^{4}$

Os conhecimentos tradicionais sobre plantas medicinais são importantes para diversos domínios científicos e tecnológicos, pois é um alvo de grande potencial na medicina tradicional. Stryphnodendron adstringens, popularmente conhecida como barbatimão, é uma planta medicinal cujas cascas do caule são utilizadas na forma de decocção ou infusão, para o tratamento de leucorréia, diarreia e como agente anti-inflamatório. ${ }^{5}$

Sideroxylon obtusifolium conhecida como "quixabeira", é utilizada na medicina popular nordestina no Brasil. $^{6}$ Sua biodiversidade exuberante e ainda pouco estudada está ameaçada de extinção, principalmente, por ação humana, na extração desenfreada de sua casca. Uma vez que, ela é popularmente empregada como agente antioxidante, hipoglicêmico e antimicrobiano. ${ }^{7}$ 
A aroeira (Myracrodruon urundeuva) é conhecida como uma espécie arbórea muito disseminada no Brasil. Pode ser encontrada na Paraíba, Pernambuco, Piauí, Rio de Janeiro, Rio grande do Norte, Sergipe, São Paulo, Tocantins e Mato grosso do Sul. É considera a madeira mais resistente do Brasil e uma das espécies mais difundida em pesquisas com fitoquímicos. ${ }^{8}$

Baseado nas atividades de extratos de plantas encontradas na literatura, este trabalho objetiva avaliar in vitro a ação dos extratos de Myracrodruom urundeuva, Stryphnodendron adstringens e Sideroxylon obtusifolium como fotossensibilizantes da terapia fotodinâmica (TFD).

\section{Materiais e Métodos}

\section{Microorganismo}

A cepa Staphylococcus aureus ATCC 25923 (American Type Culture Collection) foi reativada em meio de cultura com caldo TSB (Caldo Triptona de Soja) e mantida em estufa microbiológica SP-101/64 (SP Labor, Presidente Prudente/SP, Brasil) por 24 horas a $37^{\circ} \mathrm{C}$. Os estoques da cultura foram mantidos em criotubos a $-20^{\circ} \mathrm{C}$.

\section{Plantas e formulação das soluções fotossensibilizantes}

As folhas de $M$. urundeuva, cascas $S$. adstringens e $S$. obtusifolium coletadas em uma propriedade rural da região agreste meridional de Pernambuco - Brasil (latitude 8०17'5"'S e longitude $35^{\circ} 58^{\prime} 12^{\prime \prime} \mathrm{W}$ ), foram secas em estufa de secagem com circulação de ar por 48 horas a $40{ }^{\circ} \mathrm{C}$ e trituradas em moinho de facas tipo Willye (New Lab, Piracicaba/SP, Brasil) para serem submetidas a extrações com etanol P.A. Os extratos etanólicos obtidos foram utilizados para a elaboração das soluções fotossensibilizantes. Os extratos foram solubilizados em etanol P.A. e as diluições preparadas com água destilada esterilizada nas concentrações de 0,055; 0,01 e $0,1 \mathrm{mg} / \mathrm{mL}$.

\section{Atividade antimicrobiana}

A avaliação da atividade antimicrobiana foi realizada em microplacas de 96 poços, contendo $90 \mu \mathrm{L}$ de caldo Müeller Hinton, 10 $\mu \mathrm{L}$ do inóculo padronizado em $1 \times 10^{8} \mathrm{UFC} /$ $\mathrm{mL}$ e $100 \mu \mathrm{L}$ do extrato da planta testado como fotossensibilizante. Todos os ensaios foram realizados em triplicata.

\section{Parâmetros empregados na terapia fotodinâmica}

Para detectar condições favoráveis de ação antimicrobiana da terapia fotodinâmica utilizando como fotossensibilizantes os extratos etanólicos de $M$. urundeuva, $S$. adstringens $e$ S. obtusifolium, foi empregada uma matriz de planejamento fatorial $2^{3}$ para apresentar os pontos experimentais associados aos diferentes níveis das variáveis independentes. As mesmas foram: tempo de pré-irradiação, concentração fotossensibilizante e tempo de irradiação (Tabela 1). Por conseguinte, a variável dependente (atividade antimicrobiana) foi analisada através de um modelo de regressão logístico, dado que é uma variável dicotômica (houve, ou não houve inibição).

Tabela 1. Matriz do planejamento fatorial $2^{3}$ utilizada na disposição das variáveis independente no estudo da terapia fotodinâmica, com os extratos fotossensibilizantes de $M$. urundeuva, S. adstringens e S. obtusifolium.

\begin{tabular}{cccc}
\hline Variáveis independentes & \multicolumn{3}{c}{ Níveis } \\
\hline $\begin{array}{c}\text { Tempo de pré-irradiação } \\
\text { (minutos) }\end{array}$ & 0,0 & 2,5 & 5,0 \\
$\begin{array}{c}\text { Concentração } \\
\text { Fotossensibilizante } \\
\text { (mg/mL) }\end{array}$ & 0,01 & 0,055 & 0,1 \\
$\begin{array}{c}\text { Tempo de Irradiação } \\
\text { (segundos) }\end{array}$ & 20 & 40 & 60 \\
\hline
\end{tabular}




\section{Avaliação da terapia}

Após a aplicação do laser vermelho, o conteúdo dos poços foi semeado em placas de Petri contendo Agar Müeller Hinton com auxílio de swabs estéreis, logo, as placas foram incubadas em estufa microbiológica a $37{ }^{\circ} \mathrm{C}$ por 24 horas. Decorrido esse período, houve a observação de crescimento de unidades formadoras de colônias nas placas semeadas.

\section{Fonte de luz}

A fonte de luz foi utilizada o laser de diodo de InGaAIP, Flash Lase I (DMC Equipamentos do Brasil Ltda, São Carlos, SP- Brasil), no modo contínuo, $660 \mathrm{~nm}$ de comprimento de onda central, $100 \mathrm{~mW}$ de potência de saída, sistema de entrega através de fibra óptica com $0,028 \mathrm{~cm}^{2}$ de área de secção transversal. A irradiação foi realizada com o laser em contato com a tampa da placa de acrílico. Os detalhes dos parâmetros utilizados para a irradiação de acordo com as variáveis estão descritos na Tabela 2.

Tabela 2. Parâmetros de irradiação aplicados conforme as variáveis e níveis estudados na terapia fotodinâmica com os extratos de M. urundeuva, S. adstringens e S. obtusifolium.

\begin{tabular}{lccc}
\hline Parâmetros / Variáveis & -1 & 0 & 1 \\
\hline Irradiância & $3,5 \mathrm{~W} / \mathrm{cm}^{2}$ & $3,5 \mathrm{~W} / \mathrm{cm}^{2}$ & $3,5 \mathrm{~W} / \mathrm{cm}^{2}$ \\
Fluência & $70 \mathrm{~J} / \mathrm{cm}^{2}$ & $140 \mathrm{~J} / \mathrm{cm}^{2}$ & $210 \mathrm{~J} / \mathrm{cm}^{2}$ \\
Tempo da sessão & 20 segundos & 40 segundos & 60 segundos \\
Frequência do tratamento & Única irradiação em & Única irradiação & Única irradiação \\
& cada poço & em cada poço & em cada poço \\
Dose cumulativa administrada & $70 \mathrm{~J} / \mathrm{cm}^{2}$ & $140 \mathrm{~J} / \mathrm{cm}^{2}$ & $210 \mathrm{~J} / \mathrm{cm}^{2}$ \\
\hline
\end{tabular}

Este trabalho não precisou da aprovação do comitê de ética em pesquisa com seres humanos ou animais, pois, foram utilizados extratos vegetais frente cepa de micro-organismo ATCC.

\section{Análise estatística}

No estudo, a variável dependente ou resposta só pode assumir dois níveis ou categorias: não houve inibição (0), e houve inibição (1), relativo ao crescimento microbiano logo após a terapia fotodinâmica. Estas variáveis podem ser codificadas com números, entretanto, representam atributos e não quantidades numéricas. Por consequência, uma análise de variância baseada num planejamento experimental usual que assume normalidade não seria adequada. Um modelo apropriado para explicar o comportamento deste tipo de variáveis dependentes é o modelo de regressão logístico, que é representado pela probabilidade do evento de interesse acontecer. Esta probabilidade é dada na equação 1:

$$
P(Y=1)=\frac{1}{1+\exp \left(-\beta_{0}-\beta_{1} X_{1}-\beta_{2} X_{2}-\cdots-\beta_{p} X_{p}\right)}
$$

(Equação 1)

em que, representa uma variável resposta dicotômica, a variável independente com coeficiente do modelo com e neste caso, denota a probabilidade de haver inibição. Todas as análises foram realizadas no software $R$ (2015).

\section{Resultados}

No estudo foram usados extratos etanólicos de Myracrodruon urundeuva, Stryphnodendron adstringens e Sideroxylon obtusifolium como soluções 
fotossensibilizantes. Onde, observou-se que a cepa de Staphylococcus aureus (ATCC 25923) foi sensível à terapia fotodinâmica em distintas combinações de níveis das variáveis testadas, exceto quando o extrato de $S$. obtusifolium foi utilizado como fotossensibilizante (Tabela 3).

Observou-se que a combinação do ensaio 8 exibiu maior potencial de inibição bacteriana para os extratos de $M$. urundeuva, S. adstringens, onde, o tempo de pré-irradiação foi de 5 minutos, concentração de $100 \mu \mathrm{g} /$ $\mathrm{mL}$ e tempo de irradiação 60 segundos. Os ensaios com tempo máximo de pré-irradiação (5 minutos) e de irradiação (60 segundos) apresentaram maior incidência de inibição do crescimento de S. aureus (Tabela 3).

Tabela 3. Comportamento observado nos ensaios contendo extrato de M. urundeuva, S. adstringens e S. obtusifolium como fotossensibilizantes na técnica da TFD frente $S$. aureus, onde se indica com o sinal de (+) quando houve inibição; e (-) quando não houve inibição do crescimento microbiano.

\begin{tabular}{cccc}
\hline & \multicolumn{3}{c}{ Extratos de plantas (fotossensibilizantes) } \\
\cline { 2 - 4 } Ensaio & M. urundeuva & S. adstringens & S. obtusifolium \\
\hline 1 & - & - & - \\
2 & - & + & - \\
4 & - & - & - \\
5 & - & + & - \\
6 & + & + & - \\
7 & + & + & - \\
8 & - & + & - \\
9 & + & + & - \\
10 & - & - & - \\
11 & - & - & - \\
12 & - & - & - \\
\hline
\end{tabular}

Nas Figuras 1 e 2 são apresentados os diferentes gráficos de dispersão tridimensional das possíveis combinações dois a dois das variáveis independentes em relação às variáveis respostas inibição dos extratos de plantas $M$. urundeuva e $S$. adstringens, respectivamente. Nas Figuras 1 (b) e 2 (b) podemos observar que não houve inibição para os níveis baixos dos tempos de preirradiação e irradiação, entretanto, este comportamento não esta presente nas Figuras 1(a) e 2(a). Analogamente, podemos ver um comportamento equivalente nos níveis altos das mesmas variáveis independentes em relação à inibição.

Para cada tipo de extrato de plantas o comportamento da inibição é diferente e, por conseguinte, a relação subsequente com as variáveis independentes varia, portanto, é necessário estudá-las individualmente. 


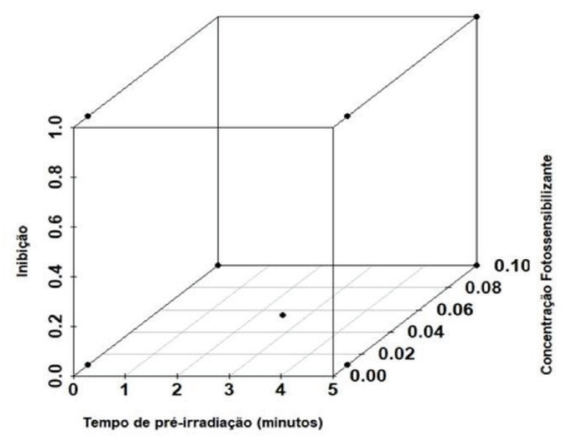

(a)

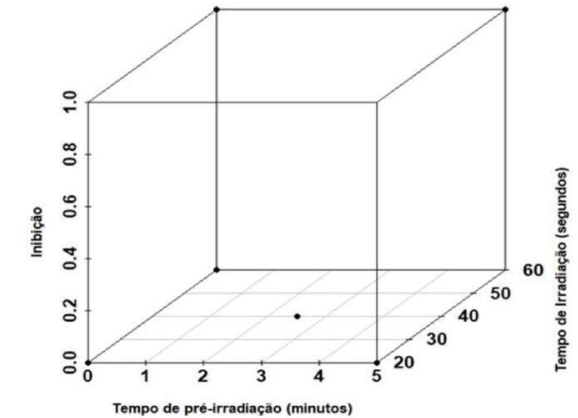

(b)

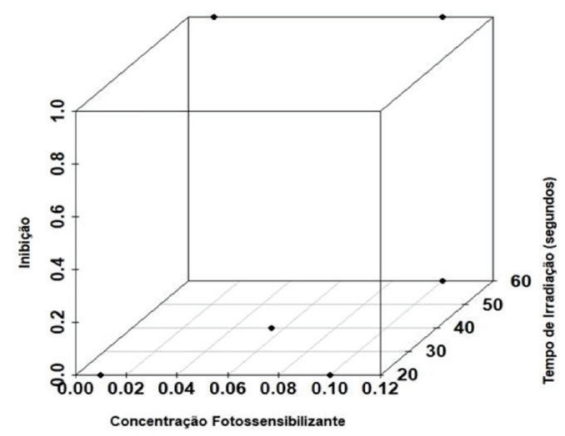

(c)

Figura 1. Gráficos de dispersão tridimensional das combinações de variáveis independentes empregadas no estudo da terapia fotodinâmica para inibição de $S$. aureus associada aos extratos de plantas $M$. urundeuva.

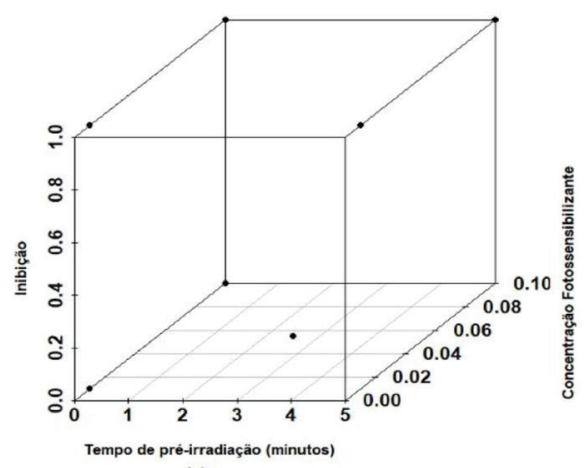

(a)

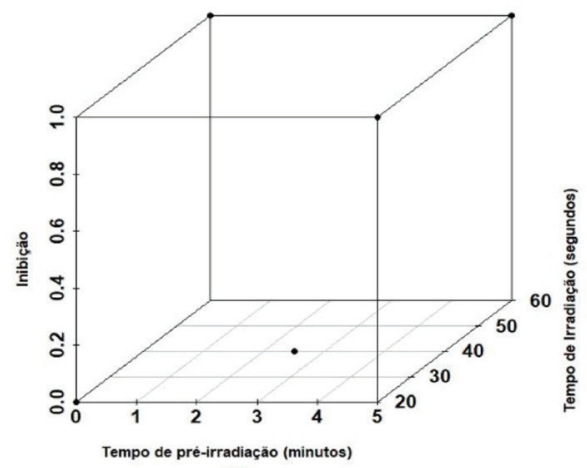

(b)

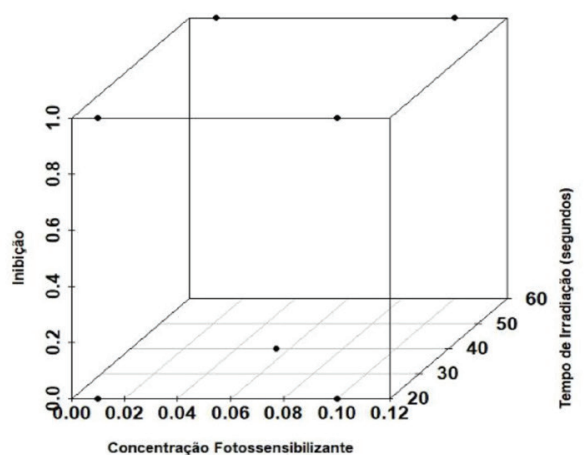

(c)

Figura 2. Gráficos de dispersão tridimensional das combinações de variáveis independentes empregadas no estudo da terapia fotodinâmica para inibição de $S$. aureus associada aos extratos de plantas $S$. adstringens. 
$\mathrm{Na}$ Tabela 3, podemos observar que não houve inibição em nenhum ponto experimental associado ao extrato de plantas $S$. obtusifolium, portanto, para as análises usando os modelos de regressão logística foram consideradas as variáveis:

$Y_{1}$ : inibição associada ao extrato da planta M. urundeuva;

$Y_{2}$ : inibição associada ao extrato da planta S. adstringens;

$X_{1}$ : tempo de pré-irradiação em minutos;

$X_{2}$ : concentração fotossensibilizante;

$X_{3}$ : tempo de Irradiação em segundos.

Os modelos ajustados para $Y_{1}$ e $Y_{2}$ são apresentados nas equações 2 e 3 :

$$
P\left(Y_{1}=1\right)=\frac{1}{1+\exp \left(118,9227-9,7766 X_{1}+543,1467 X_{2}-2,4789 X_{3}\right)}
$$

(Equação 2)

e

$$
P\left(Y_{2}=1\right)=\frac{1}{1+\exp \left(272,4228-59,4964 X_{1}-1,6853 \times 10^{-07} X_{2}-4,9580 X_{3}+0,9916 X_{1} X_{3}\right)},
$$

(Equação 3)

Na Tabela 4, apresentamos os valores da variável resposta, os valores obtidos pelo modelo ajustado e os resíduos para cada uma das variáveis. É possível observar que foram obtidos dois modelos estatísticos que permitem predizer se houve ou não houve inibição do crescimento de $S$. aureus utilizando os extratos de $M$. urundeuva e $S$. adstringens. Além do que, todos os resíduos foram zero, indicando que os modelos tem excelente poder de predição nas regiões experimentadas. 
Patricia Lins AzeVedo do Nascimento et al.

Tabela 4. Valores observados, ajustados, e resíduos associados aos modelos representados nas equações 2 e 3 sobre inibição de $S$. aureus por $M$. urundeuva e $S$. adstringens.

\begin{tabular}{ccccccc}
\hline Ensaio & & & & & & \\
\hline 1 & 0,00 & 0,00 & 0,00 & 0,00 & 0,00 & 0,00 \\
2 & 0,00 & 0,00 & 0,00 & 1,00 & 1,00 & 0,00 \\
3 & 0,00 & 0,00 & 0,00 & 0,00 & 0,00 & 0,00 \\
4 & 0,00 & 0,00 & 0,00 & 1,00 & 1,00 & 0,00 \\
5 & 1,00 & 1,00 & 0,00 & 1,00 & 1,00 & 0,00 \\
6 & 1,00 & 1,00 & 0,00 & 1,00 & 1,00 & 0,00 \\
7 & 0,00 & 0,00 & 0,00 & 1,00 & 1,00 & 0,00 \\
8 & 1,00 & 1,00 & 0,00 & 1,00 & 1,00 & 0,00 \\
9 & 0,00 & 0,00 & 0,00 & 0,00 & 0,00 & 0,00 \\
10 & 0,00 & 0,00 & 0,00 & 0,00 & 0,00 & 0,00 \\
11 & 0,00 & 0,00 & 0,00 & 0,00 & 0,00 & 0,00 \\
12 & 0,00 & 0,00 & 0,00 & 0,00 & 0,00 & 0,00 \\
\hline
\end{tabular}

\section{Discussão}

Os três principais elementos da TFD são o fotossensibilizante, a luz visível e o oxigênio, estes elementos, quando combinados, produzem espécies oxidantes potentes. ${ }^{9}$ Nos últimos anos, muitos estudos demonstraram que os fitoquímicos exercem a sua atividade antibacteriana através de diferentes mecanismos de ação, tais como, danos na membrana bacteriana e supressão de fatores de virulência, incluindo inibição da atividade de enzimas e toxinas, e de formação de biofilmes bacterianos. ${ }^{10}$ Baseado nestas considerações, o presente estudo avaliou o potencial fotossensibilizante de três extratos de plantas na técnica da TFD, frente $S$. aureus.

A avaliação da atividade antimicrobiana dos extratos brutos etanólicos de plantas descritas neste estudo corrobora com a tendência atual de se desenvolver e testar medicamentos produzidos a partir de plantas. 11,12 Inclusive, percentual inibitório encontrado nos resultados deste estudo, está em concordância com a atividade antimicrobiana encontrada por outros autores. ${ }^{10,13,14}$
Dessa forma, a utilização de plantas medicinais surge como uma alternativa promissora na terapia fotodinâmica, visto que sua ação antimicrobiana é potencializada mediante a aplicação do laser vermelho. Assim, a TFD age de forma notavelmente mais rápida contra micro-organismos do que antimicrobianos isolados. ${ }^{2,15}$

Segundo Dai e colaboradores ${ }^{16}$, a TFD proporciona vantagens significativas em relação às terapêuticas antimicrobianas existentes. O motivo pelo qual existe resistência bacteriana a drogas antimicrobianas convencionais é seu único sítio e modo de ação. Assim, após determinada exposição, a maioria dos micro-organismos começa a desenvolver mecanismos de resistência para um único ponto de ataque. Entretanto os fotossensibilizadores agem via produção de oxigênio singleto ou espécies reativas de oxigênio, os quais não apresentam uma especificidade de ação celular. Devido a essa inespecificidade de ação, o micro-organismo não é capaz de desenvolver resistência.

M. urundeuva, um dos extratos utilizados no presente estudo, alcançou um 
potencial inibitório considerável, apesar de o resultado obtido ser inferior a $50 \%$ de inibição. Apresentaram-se com a maior inibição bacteriana os ensaios submetidos ao tempo de pré-irradiação de 5 minutos, concentração de $100 \mu \mathrm{g} / \mathrm{mL}$ e tempo de irradiação de 60 segundos. Sua reputação antimicrobiana aqui exposta está em concordância com outros estudos, que demonstraram que os extratos hidro-alcoólicos de casca de tronco de $M$. urundeuva exercem atividade antiinflamatória em vários modelos experimentais de inflamação. Também foram relatadas atividades antioxidantes, antibacteriana, antifúngicas e analgésicas. ${ }^{13,17}$

$S$. adstringens destacou-se nesta pesquisa devido ao seu potencial inibitório apresentado ser superior aos demais. Ambas as concentrações, $100 \mu \mathrm{g} / \mathrm{mL}$ e $10 \mu \mathrm{g} / \mathrm{mL}$, não apresentaram divergências de resultados entre si. Tiveram inibições análogas. Entretanto, o efeito inibitório com o tempo de pré-irradiação de 5 minutos e o tempo de irradiação de 60 s segundos foi superior. Este resultado está em conformidade com pesquisas que demonstram várias de suas atividades, tais como anti-inflamatória, antisséptica e antibacteriana. ${ }^{14,18,}$ ${ }^{19} \mathrm{De}$ acordo com Souza et al. ${ }^{20}$, o efeito antimicrobiano do extrato $S$. adstringens pode ser atribuído ao alto teor de taninos, que apresentam potencial para impedir a adesão bacteriana e de inibição enzimática.

O presente estudo constatou o potencial inativante do fotossensibilizante de S. obtusifolium frente à cepa de $S$. aureus, não foram observadas divergências nos resultados, uma vez que, todos os ensaios contiveram grande crescimento bacteriano. Apresentando concordância com Eller et al. ${ }^{21}$, que avaliaram a atividade antimicrobiana interativa, in vitro, de alguns extratos. Dentre eles o da quixaba ( $S$. obtusifolium) frente $S$. aureus, concluindo que o extrato não apresentou atividade antimicrobiana frente a cepa testada. Em estudo seme-
Ihante, Costa et al. ${ }^{22}$, avaliaram alguns extratos de plantas e S. obtusifolium apresentou o menor potencial inibitório comparado com as demais. Apesar desses autores acima não terem submetido o estudo a TFD, o extrato $S$. obtusifolium se mostrou ineficiente em perspectiva antibacteriana.

A cepa em estudo, Staphylococcus aureus, é uma bactéria gram-positiva, e um dos patógenos mais frequentemente identificados em associação com infecções, particularmente adquirida em hospitais, dos quais numerosos subtipos são identificados como resistentes à meticilina. ${ }^{23}$ Frente isso, novas perspectivas no desenvolvimento de terapias para controlar este patógeno são discutidas atualmente e apesar da crescente ocorrência de resistência aos antibióticos, há relatos na literatura de susceptibilidade de micro-organismos à fotoinativação. ${ }^{9,24}$

Em estudo semelhante a este, Ferraz et al. ${ }^{25}$, obtiveram redução microbiana eficaz de cerca de $98 \%$ de Staphylococcus aureus utilizando a quimioluminescência como fonte de luz e o tempo de iluminação variou de 60 a 240 minutos. Apesar do fotossensibilizante ser distinto deste estudo, pode-se enfatizar o tempo de iluminação utilizado. Conseguiu-se o mesmo sucesso da terapia, inibição do S. aureus, com tempos de irradiação bastante inferiores, variando de 20 a 60 segundos, subtemendo o teste ao laser vermelho em um comprimento de onda de $660 \mathrm{~nm}$ e fluência de 70, 140 e 210 $\mathrm{J} / \mathrm{cm}^{2}$ e potência de $100 \mathrm{~mW}$. Dessa forma a utilização de laser como fonte de luz em TFD, ainda se torna a opção mais viável.

Bartolomeu et al. ${ }^{26}$, com o objetivo de avaliar o efeito da TFD sobre os fatores de virulência de $S$. aureus e o potencial desenvolvimento de resistência dessa bactéria observaram que as bactérias sobreviventes não desenvolveram resistência e a TFD e contrariamente aos antibióticos tradicionais, tiveram a expressão de fatores de virulência inibida. 
Assim como Kossakowska et al. ${ }^{27}$, teve como um dos objetivos investigar a virulência da cepa de $S$. aureus como também a resistência à meticilina. Os dados obtidos permitiram demonstrar a eliminação da resistência a fotoinativação de $S$. aureus e que ambas as cepas, altamente virulentas e pouco virulentas, poderiam ser facilmente erradicadas com o uso de TFD.

\section{Conclusão}

Os extratos etanólicos de barbatimão e aroeira advindos do agreste de Pernambuco demonstram ser ativos como fotossensibilizantes na técnica da terapia fotodinâmica. A partir do encontrado no estudo são apresentados dois modelos estatísticos que permitem predizer de forma adequada a ação antimicrobiana dos extratos de $M$. urundeuva e $S$. adstringens como fotossensibilizantes nas condições experimentais testadas. Todavia, novos ensaios de toxicidade deverão ser realizados para futura indicação destes extratos na técnica da TFD como uma alternativa ao uso de antibióticos no controle de crescimento de micro-organismos patogênicos.

\section{Agradecimentos}

Ao Centro Universitário Tabosa de Almeida - ASCES/UNITA, à FACEPE, à Universidade de Pernambuco (Campus Garanhuns) e a Unidade Acadêmica de Garanhuns - UAG/UFRPE.

\section{Declaração de Divulgação de Autor}

Não existem interesses financeiros concorrentes.

\section{REFERÊNCIAS}

1. Miyabe $M$, Junqueira JC, Costa $A C$, Jorge AO, Ribeiro MS, Feist IS. Effect of photodynamic therapy on clinical isolates of Staphylococcus spp. Braz Oral Res. 2011, 25: 230-34.

http://dx.doi.org/10.1590/S1806-

83242011005000006

2. Oniszczukm A, Kulesza KAW, Oniszczuk T, Kasprazak K. The potential of Photodynamic Therapy (PDT) - Experimental investigations and clinical use. Biomed Pharmacother. 2016, 83: 912-29.

https://doi.org/10.1016/j.biopha.2016.07.058

3. Ali AJ, Saliem SS. Photodynamic therapy and periodontology. J Bagh Cool Dentistry. 2016, 28: 69-72.

https://doi.org/10.12816/0028224

4. Hamblin MR, Hasan T. Photodynamic therapy: a new antimicrobial approach to infectious disease? Photochem Photobiol Sci. 2004, 3(5): 436-50.

https://doi.org/10.1039/b311900a

5. Lima JCS, Martins DTO, Souza PT. Experimental evaluation of stem barck of Stryphonodendron adstringens (Mart.) coville for anti inflammatory activity. Phytother Res. 1998, 12: 218-20.

https://doi.org/10.1002/(SICl)10991573(199805)12:3\%3C218::AIDPTR220\%3E3.0.CO;2-4

6. Aquino PEA, Magalhães TR, Nicolau LAD, Leal LKAM, Aquino NC, Santos SM. The anti-inflamatory effects of $\mathrm{N}$-methyl-(2S,4R)-trans-4-hydroxy-_-proline from Syderoxylon obtusifolium are related to its inhibition of TNF-alpha and inflammatory enzymes. Phymed. 2017, 24:14-23. http://dx.doi.org/10.1016/j.phymed.2016.11.010

7. Pereira JV, Freires IA, Castilho AR, Cunha MG, Alves HS, Rosalen PL. Antifungal potencial of Sideroxulon obtusifolium and Syzygium comini and their mode of action against Candida Albicans. Pharm Biol. 2016, 54: 2312-19. https://doi.org/10.3109/13880209.2016.1155629

8. Canuto DSO, Silva AM, Freitas MLM, Sebbenn AM, Moraes MLT. Genetic variability in Mycrodruon urundeuva (Allemão) Engl. progeny test. 
Scient Res Pub. 2016, 7: 1-10.

http://dx.doi.org/10.4236/ojf.2017.71001

9. Denis TGS, Dai T, Izikson L, Astrakas C, Anderson RR, Hamblin MR, et al. Antimicrobial photoinactivation as an evolving and emerging discovery strategy against infectious disease. Virulence. 2011, 2: 509-20.

https://doi.org/10.4161/viru.2.6.17889

10. Barbieri R, Coppo E, Marchese A, Daglia M, Sobarzo-Sánchez E, Nabavi SF, et al. Phytochemicals for human disease: An update on plant-derived compounds antibacterial activity. Microbiol Res. 2016, 196: 44-68.

https://doi.org/10.1016/j.micres.2016.12.003

11. Cartaxo SL, Souza MMA, Albuquerque UP. Medicinal plants with bioprospecting potential used in semi-arid northeastern Brazil. J Ethnopharmacol. 2010, 131: 326-42.

https://doi.org/10.1016/j.jep.2010.07.003

12. Dutra RC, Campos MM, Santos ARS, Calixto JB. Medicinal plants in Brazil: Pharmacological studies drug discovery, challenges and perspectives. Pharmacol Res. 2016, 11: 24-29. https://doi.org/10.1016/j.phrs.2016.01.021

13. Botelho MA, Rao VS, Carvalho CBM. Lippia sidoides and Myracrodruon urundeuva gel prevents alveolar bone resorption in experimental periodontitis in rats. J Ethnopharmacol. 2007, 113: 471-78.

https://doi.org/10.1016/j.jep.2007.07.010

14. Costa MA, Ishida K, Kaplum V, Koslyk ED, de Mello JC, Ueda-Nakamura T, et al. Safety evaluation of proanthocyanidin polymer-rich fraction obtained from stem bark of Stryphnodendron adstringens (BARBATIMÃO) for use as a pharmacological agent. Reg Toxicol Pharmacol. 2010, 58: 330-35.

https://doi.org/10.1016/j.yrtph.2010.07.006

15. Saraiva ME, UlissesAVRA, Ribeiro DA, et al. Plant species as a therapeutic resource in areas of the savanna in the state of Pernambuco,
Northeast Brazil. J Ethnopharmacol. 2015, 171: 141-53.

https://doi.org/10.1016/j.jep.2015.05.034

16. Dai T, Tegos GP, Zhiyentayev T, Mylonakis E, Hamblin MR. Photodynamic therapy for methicillin-resistant Staphylococcus aureus infection in a mouse skin abrasion model. Lasers Surg Med. 2010, 42: 38-44.

https://doi.org/10.1002/lsm.20887

17. Napoleão TH, Gomes FS, Lima TA, Santos NDL, Sá RA, Albuquerque AC, et al. Termiticidal activity of lectins from Myracrodruon urundeuva against Nasutitermes corniger and its mechanisms. Int Biodeter Biodegr. 2011, 65: 52-59. https://doi.org/10.1016/j.ibiod.2010.05.015

18. Albuquerque UP, Monteiro JM, Ramos MA, Amorim ELC. Medicinal and magic plants from a public market in northeastern Brazil. J Ethnopharmacol. 2007, 110: 76-91.

https://doi.org/10.1016/j.jep.2006.09.010

19. Agra MF, Silva KN, Basílio IJLD, Freitas PF, FiIho JMB. Survey of medicinal plants used in the region Northeast of Brazil. Braz. J. Pharmacog. 2008,18: 472-08.

http://dx.doi.org/10.1590/S0102-

695X2008000300023

20. Souza NC, Gomes MN, Maciel RRG. Evaluation of the Antimicrobial Activity of Stryphnodendron barbatiman against Citrobacter freundii. Mat Sci Applic. 2013, 4: 780-85.

http://dx.doi.org/10.4236/msa.2013.412099

21. Eller SCWS, Feitosa YA, Arruda TA, Antunes RMP, Catão R MR. Avaliação antimicrobiana de extratos vegetais e possível interação farmacológica in vitro. Rev Ciênc Farm Básica Apl. 2015, 36: 131-36.

http://seer.fcfar.unesp.br/rcfba/index.php/rcfba/ article/view/218/126

22. Costa EMMB, Barbosa AS, Arruda TA. Estudo in vitro da ação antimicrobiana de extratos de plantas contra Enterococcus faecalis. Bras Patol Med Lab. 2010, 46: 175-80. 
http://www.scielo.br/pdf/jbpml/v46n3/a04v46n3. pdf

23. Filho ALNF, Carneiro VSM, Souza EA, Santos RL, Catão MHCV, Medeiros ACD. In vitro evaluation of antimicrobial photodynamic therapy associated with hydroalcoholic extracts of Schinopsis brasiliensis Engl.: New therapeutic perspectives. Photomed Laser Surg. 2015, 33: 240-45.

https://doi.org/10.1089/pho.2014.3796

24. Ruela HS, Leal ICR, Almeida MRA, Santos KRN, Wessjohann LA, Kuster RM. Antibacterial and antioxidant activities and acute toxicity of Bumelia sartorum, a Brazilian medicinal plant. Braz J Pharma. 2011, 21: 86-91. http://dx.doi.org/10.1590/S0102695X2011005000035

25. Ferraz RC, Fontana CR, Ribeiro AP, Trindade FZ, Bartoloni FH, Baader JW, et al. Chemilumi- nescence as a PDT light source for microbial control. J Photochem Photobiol. 2011,103: 87-92.

https://doi.org/10.1016/j.jphotobiol.2011.01.018

26. Bartolomeu M, Rocha S, Cunha A, Neves MGPMS, Faustino MAF, Almeida A. Effect of photodynamic therapy on the virulence factors of Staphylococcus aureus. Front Microbiol. 2016, 7: 267.

https://doi.org/10.3389/fmicb.2016.00267

27. Kossakowska M, Nakonieczna J, Kawiak A, Kurlenda J, Bielawski KP, Grinholc M. Discovering the mechanisms of strain-dependent response of Staphylococcus aureus to photoinactivation: oxidative stress toleration, endogenous porphyrin level and strain's virulence. Photodiagnosis Photodyn Ther. 2013, 10(4): 348-55. https://doi.org/10.1016/j.pdpdt.2013.02.004

Submetido em: 14-10-2018

Aceito em: 18-12-2018 